\title{
Research on Internal Audit of Enterprise Knowledge Management
}

\author{
Zhihong Zhu \\ Institute of Petroleum Economics and Management \\ Northeast Petroleum University \\ Daqing, China \\ Zzh79@126.com
}

\author{
Dawei Xue \\ Institute of Petroleum Economics and Management \\ Northeast Petroleum University \\ Daqing, China \\ dqxuedawei@126.com
}

\begin{abstract}
Internal audit of enterprise knowledge management is the first link of enterprise knowledge management. Research on internal audit of enterprise knowledge management is of great significance on the successful implementation of enterprise knowledge management. This article explained the concept, content, processes, methods and report of internal audit of enterprise knowledge management.
\end{abstract}

Keywords-audit of knowledge management; internal audit; process; method; report

\section{INTRODUCTION}

Knowledge management as an important management thought is concerned more and more by organizations, along with access to knowledge economy era in the 1990s. Knowledge management is a conscious strategy to be taken. It can ensure that most in need of the knowledge is transmitted to those most in need in most of the time required, which can help people to share knowledge, and thus be adopted into practice in different ways, and achieve the ultimate aim of improving performance of enterprise in the end. The implementation of knowledge management has set off a wave in recent years. However, current statistics show that many enterprises is not satisfied with the implementation of knowledge management projects. The success rate is only up to fifteen percent. The reason is that these enterprises did not clarify the situation of their existing knowledge and potential knowledge, and did not fully clear the need for knowledge and the ability of their knowledge management before the implementation of knowledge management. [1] Therefore, the internal audit of knowledge management should be as the primary aspect of enterprise knowledge management. The internal audit of knowledge management has great significance to the enterprises in the era of knowledge economy. Enterprises only understand their base and demand of knowledge, and build knowledge capacity on the basis, then can work out a reasonable and effective knowledge management strategy, which can provide a good knowledge background for the longterm development.

\section{CONCEPT OF INTERNAL AUDIT OF ENTERPRISE KNOWLEDGE MANAGEMENT}

Internal audit of knowledge management is a dynamic process, which is an important element in knowledge management practice activities. It refers to a kind of activity of combination of audit and knowledge management, in which the knowledge management responsibility organs or personnel research and evaluate systematically and scientifically corporate knowledge resources according to certain procedures and methods, and analysis the base and demand of organizational knowledge, and made the diagnostic and predictive auditing report, in order to improve management quality and the management level and efficiency, thus promoting the performance of knowledge management.

\section{CONTENT OF INTERNAL AUDIT OF ENTERPRISE KNOWLEDGE MANAGEMENT}

The content of internal audit of enterprise knowledge management includes knowledge body (people), knowledge object (namely knowledge itself) and knowledge environment. [2]

\section{A. People}

People is the owner of the knowledge, and the receiver of knowledge. Note that the people not only refers to the organizational knowledge workers, but also including the knowledge body of value chain of organization, such as customer, supplier and so on. The internal audit of enterprise knowledge management one hand must be familiar with the work contents and targets of various department of enterprise, in order to determine the knowledge demand, on the other hand audit knowledge process and each relationship of people, etc.

\section{B. Knowledge}

Knowledge include explicit knowledge and tacit knowledge. Explicit knowledge is that people can be taught through oral, textbooks, reference materials, journals, patents, literature, audio-visual media, software and database access etc., but also through the encoding modes such as language, books, text, databases, etc., which can easily been learned by people. Tacit knowledge is in the human brain, which is accumulated in the long-term practice and is closely related to the personal experience, which often is some skills, and is not easily expressed by using language and is not easily learned from others. When the internal auditors audit knowledge, they not only audit explicit knowledge, but also tacit knowledge. It is necessary to capture tacit knowledge in the audit process. 


\section{Knowledge Environment}

Knowledge environment has the role of promoting or hindering to knowledge activity. Knowledge environment has two aspects: technical environment and organizational environment. Technical environment refers mainly to information technology, for IT is understandable. The organizational environment include organizational design and organizational culture. Organizational design refers to the organizational process and structure, organizational culture indirectly reflect the culture of sharing knowledge and organizational values.

\section{PROCESS OF INTERNAL AUDIT OF ENTERPRISE KNOWLEDGE MANAGEMENT}

Internal audit of enterprise knowledge management is a dynamic process. In general the process of complete internal audit of enterprise knowledge management consists of three phases. They are planning stage, the implementation phase, the completion stage.

\section{A. Planning Stage}

The planning stage of internal audit of knowledge management is the starting point of the entire audit work. In order to achieve the desired objectives of audit, the internal auditor must make a scientific and reasonable audit plan to ensure the investigation and evidence collection work before implementing the audit process. The main work of planning stage to be done as follows: a preliminary understanding of the basic situation of the audited unit, including the financial budget, organizational infrastructure, etc. ; to understand the basic concepts and attitude of the senior management personnel of audited department for knowledge management to determine the degree of attention for knowledge management; to understand the organization of audited unit, that is , the overall framework of planning, coordinating and controlling, to determine the knowledge needs; to understand enterprise culture, policies and practices of personnel of audited unit, to determine the extent of knowledge sharing and organizational values; to understand the process of acquiring, disseminating and sharing knowledge, to define the audit objectives of knowledge management, to standardize the audit purpose and object, to determine the index system of internal audit of enterprise knowledge management; a preliminary assessment of knowledge assets; the formulation of a preliminary audit strategy; to choice auditing methods; the preparation of plan of internal audit of enterprise knowledge management.

\section{B. Implementation Phase}

The implementation phase of internal audit of knowledge management is the intermediate process, in which to obtain evidence according to the scope, main points, steps and methods of internal audit of knowledge management, then to form audit conclusion and to achieve the audit goal. The main work of implementation stage to be done as follows: to collect data through questionnaires, personal interview, focus groups meeting or using knowledge management software system, in order to determine the explicit knowledge and tacit knowledge and to determine the actual and potential knowledge wealth. To analyze the collected data using general analysis, strategic importance analysis or data flow chart analysis method; to analysis and evaluate the problems and opportunities showed by data.

\section{Completion Stage}

The completion stage of internal audit of knowledge management is the substantive completion stage of the project, in which it is necessary to collate and evaluate the data after audit of knowledge management, then to form audit opinions and suggestions and to prepare internal audit report of knowledge management. The main work of completion stage to be done as follows: to evaluate the audit evidence obtained from implementation of the audit process; to evaluate the quality and relevance of knowledge content of documents and information systems; to evaluate the use of the technology aimed at improving the speed, efficiency and safety of knowledge document processing; to evaluate the opportunities, frequency and incentive mechanism of knowledge exchange and so on; to draw knowledge maps in order to reveal the organizational knowledge state, knowledge flow, knowledge networks and so on, then to analyze the organizational knowledge gap; to form an audit opinion based on the index system of internal audit of knowledge management and to prepare internal audit report of knowledge management and to put forward a reasonable proposal for solving the problems of organizational knowledge.

\section{METHOD OF INTERNAL AUdiT OF ENTERPRISE KNOWLEDGE MANAGEMENT}

\section{A. Knowledge Management Statistical Evaluation Method}

It is the method that quantitate the identification, storage, use and innovation of knowledge with expression of knowledge monetary number. Such as knowledge is distributed by cumulation (With application module and departments for the unit, to display the statistics accumulated valid documents with chart); knowledge is distributed by cycle (With application module and departments for the unit, to display the statistics valid knowledge documents by monthly, quarterly, annually with chart); knowledge is distributed by growth (to provide comparison charts, comparing with modules and department according to cycle).

\section{B. Indicators Measure Method}

The essence of audit is to compare the realistic situation with established standards, then to evaluate the efficiency and effectiveness. If you want to assess the efficiency and effectiveness of enterprise knowledge management, it is necessary to establish knowledge management indicators measure card and to assess organizational knowledge management through quantitative means.

\section{HyA-K-Audit Method}

HyA-K-Audit method is put forward by by Dr. Ann Hylton. It is people-centered knowledge management audit, which assess the level of the knowledge propagation, use and sharing from the two aspects of efficiency and effectiveness. The three steps of HyA-K-Audit method implementation as follow: 
Knowledge -Survey, Knowledge-Inventory and KnowledgeMap.

\section{Other Methods}

Apart from the above-mentioned three methods, there are some other methods of internal audit of knowledge management, such as the traditional auditing methods. According to the theory of modern audit, the methods of obtaining audit evidence have six kinds. They are inspection, calculation, observation, query, confirmation, counting and analytical review. These traditional audit methods still apply to knowledge management audit. For example, we can learn enterprise technology environment, organizational design and organizational culture; etc. by asking and observation. We can verify the accuracy of knowledge capital accounting by inspection, calculation and analytical review. Such as Jay Liebowitz, etc. knowledge management auditing methods. Dr. Jay Liebowitz is a professor of Maryland-BaltimoCounty University, who also is a expert of studying knowledge management system methodology. Jay Liebowitz etc. put forward knowledge the knowledge management audit methods with three steps. Such as the auditing methods of David Skyrme. David Skyrme is a consultant. His audit method is affected by information audit. He uses the principle of information resources management to knowledge audit. His knowledge management audit differ the order of the importance knowledge assets by analyzing the core business processes and critical areas of management decision-making. In addition, the knowledge management audit approach proposed by Amrit Tiwana give us a set of knowledge assessment tools, which audit knowledge from many aspects such as basic facilities, process, technology, organizational culture and reputation.

\section{ACKNOWLEDGMENT}

Fund projects: Chinese Ministry of Education Humanities Social Science Fund Project (11YJC630147); Heilongjiang Province Philosophy Social Science Research Planning Project (12E051). Institute of petroleum economics and management key project of Heilongjiang university and social science research base (JD20121213).

\section{REFERENCES}

[1] FengJing. The First Step of Knowledge Management Implementation—Knowledge Audit [J]. Information Science, 2010, (5).

[2] Ann Hylton. "Measuring \& Assessing Knowledge-Value \& the Pivotal Role of Knowledge Audit", At: http://www.knowledgeboard.com.

[3] DuMao-bao, TianLi-jun, WangXiao-qin. Research on Knowledge Management Audit Report. [J]. China Management Informationization. 2011, (9). 